\title{
A EVOLUÇÃO DA BALANÇA ANALÍTICA
}

Júlio Carlos Afonso* e Raquel Medeiros da Silva

Departamento de Química Analítica, Instituto de Química, Universidade Federal do Rio de Janeiro, CP 68563, 21949-900 Rio de Janeiro - RJ

Recebido em 12/8/03; aceito em 6/2/04; publicado na web em 17/06/04

THE EVOLUTION OF THE ANALYTICAL BALANCE. This work intends to describe the historical evolution of the balance based on its technical improvement. This instrument has always been used for commercial and industrial purposes, but its value in research and chemistry was only recognized much later. The classical balance was the two-pan model for about 40 centuries, but when its importance in chemistry was established, particularly beginning at the end of the XVIIIth century, many improvements were made in order to increase sensitivity and shorten the weighing procedure. The balance design greatly changed along the XXth century: the classical two-pan models were replaced by one-pan balances that were replaced by electronic instruments.

Keywords: balance; evolution; mass determination.

\section{INTRODUÇÃ̃O}

Quando se fala em balança, dois termos vêm à mente: massa e peso. Eles são geralmente usados como sinônimos devido ao senso comum. Todavia, o rigor exige a diferenciação entre ambos. A massa de um objeto pode ser determinada pela medida de sua inércia. Inércia é a resistência de um objeto a um esforço realizado para modificar seu estado de movimento. A massa é uma propriedade intrínseca do corpo, não varia conforme o local onde ele se encontre. Ela é escalar e sua unidade no sistema internacional de unidades (SI) é o quilograma $(\mathrm{kg})$. Já o peso é uma força que depende da massa do objeto, além de depender da massa do planeta e da distância entre o objeto e o centro do astro (centro de massa). O peso é vetorial e sua unidade SI é o newton $(\mathrm{N})$. Se a massa de um corpo é $m$, o seu peso é definido por $P=m g$, em que $g$ é aceleração da gravidade no local onde se encontra o corpo. O peso de um corpo depende de sua posição, porque $g$ varia de ponto a ponto. Na análise quantitativa o interesse recai na quantidade de matéria contida no corpo, isto é, na sua massa. A balança, estritamente, determina massa e não peso.

Uma das maiores dificuldades que os alunos do ensino médio e fundamental enfrentam ao estudar as reações químicas está relacionada à grande extensão e generalidade do conceito de massa. Essa dificuldade faz com que os alunos, muitas vezes, não reconheçam o papel dos reagentes e produtos ${ }^{1}$. Nessa perspectiva, cabe relembrar o Princípio da Conservação da Matéria ${ }^{2-4}$, onde a figura de Antoine Laurent Lavoisier (1743-1794), em sua obra Traité Elementaire de Chimie (1789), tem importância central. Embora não tenha sido o primeiro a enunciá-lo, e nem o tenha fundamentado experimentalmente, Lavoisier supôs que esse princípio fosse válido para qualquer reação química em um sistema fechado, utilizando-o como ferramenta para a investigação e a teoria química ${ }^{4}$. De fato, desde antes de Lavoisier (na chamada época pré-clássica da química), já se tinha atenção para as proporções de massa em processos químicos, ainda que de maneira empírica e em casos isolados como, por exemplo, nos trabalhos de Johann Baptist van Helmont (1577-1644) com a prata $^{2}$.

*e-mail: julio@iq.ufrj.br

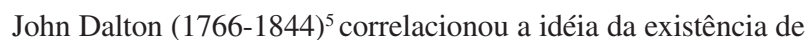
elementos, que não podem ser decompostos quimicamente, à idéia dos átomos, que são indivisíveis. Ele afirmou que cada espécie de átomo deve ter suas propriedades específicas - em particular, uma massa característica. Essas idéias podiam ser usadas para interpretar fatos químicos em uma base quantitativa. Sua teoria atômica justificava as leis da conservação da massa, das proporções definidas e das proporções múltiplas, estas últimas propostas no início do século XIX.

Estas leis relacionam as massas das substâncias que participam de uma reação química e fizeram a Química ingressar em uma nova era, pois as teorias passaram a ser fundamentadas em experiências, em que a balança desempenhava papel primordial.

\section{PRINCÍPIO DE FUNCIONAMENTO DE UMA BALANÇA MECÂNICA}

A balança é empregada em uma operação denominada pesagem; esta é realizada mediante a comparação direta entre dois objetos, um de massa conhecida e outro de massa desconhecida. A balança, com efeito, nada mais é do que uma alavanca. Alavanca é qualquer barra rígida capaz de se mover em torno de um ponto, denominado ponto de apoio.

Conforme a posição relativa da força motriz, da força resistente e do ponto de apoio ${ }^{6}$ tem-se três tipos de alavancas: interfixa; interresistente e intermotriz. $\mathrm{O}$ interesse recai no funcionamento da alavanca interfixa, para a descrição das características essenciais da balança: o ponto de apoio situa-se entre a força motriz e a resistência.

Quanto à condição de equilíbrio nas alavancas, diz-se que um corpo está em equilíbrio mecânico quando duas condições são obedecidas $^{6}$ : a resultante das forças que agem sobre o corpo deve ser nula e o momento resultante das forças que agem sobre o corpo também deve ser nulo.

A balança mecânica (Figura 1) tem um travessão rígido e um ponto de apoio central, onde se liga uma haste oscilante (fiel), cuja ponta percorre uma escala de fundo graduada. O travessão é dividido em dois segmentos, denominados braços; em cada extremidade do travessão há um prisma que suporta o prato da balança por meio de uma suspensão adequada ${ }^{6}$. 


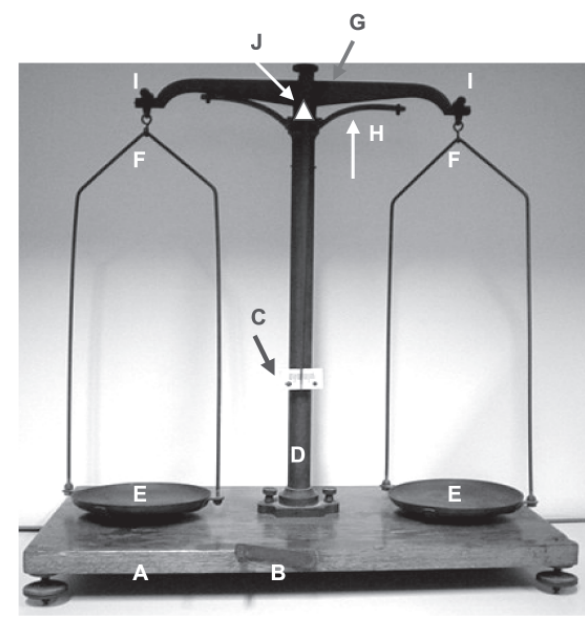

Figura 1. A balança tradicional de dois pratos e seus componentes básicos: A: base (ou plataforma), que contém três pontos de apoio; B: comando que trava ou destrava a balança; $C$ : escala de fundo. No meio dessa escala, vêse a ponta do fiel da balança; D: haste da balança; E: pratos; $F$ : suportes dos pratos; G: travessão, que é divido em duas partes iguais, denominadas braços; H: barra amortecedora do travessão; I: prismas dos suportes dos pratos; J: marca que assinala a localização do ponto de apoio central (oculto na figura), onde se apóia o travessão

A Figura 2 mostra o diagrama básico das forças que atuam na balança. $\mathrm{AB}$ representa o travessão do instrumento, dividido em dois segmentos, $\mathrm{AO}$ e OB. O é o ponto de apoio do travessão. Ao se colocar um objeto no prato da direita, o ponteiro sofrerá uma deflexão para a esquerda pela ação da força peso (G'); o segmento OB desce, descrevendo um arco BB'. Em contraposição, o outro segmento sobe, descrevendo um arco AA' de mesma magnitude de BB'. O fiel da balança (representado pelo segmento de reta OT) desloca-se para a esquerda (segmento OS). A força peso G, necessária para restabelecer o equilíbrio original, é obtida ao se colocar no prato da esquerda, corpos de massas conhecidas, chamados "pesos". A Figura 3 mostra a apresentação clássica desses "pesos".

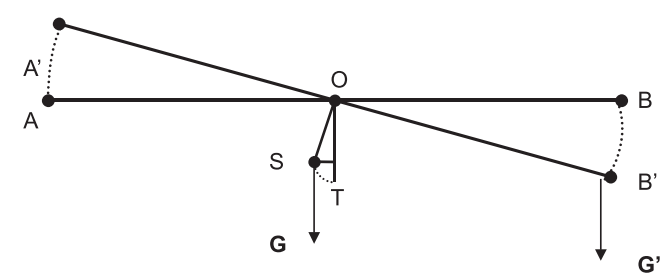

Figura 2. Diagrama de forças que atuam na balança em uso

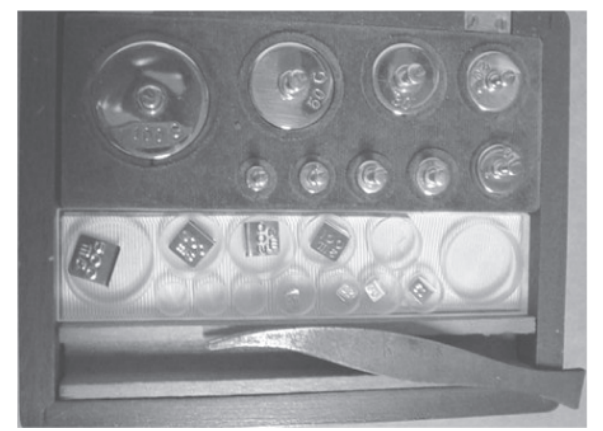

Figura 3. A clássica caixa de pesos de uma balança de dois pratos (os pesos inferiores a $1 \mathrm{~g}$ eram denominados pesos fracionários), acompanhada de pinça de manipulação
Quando o equilíbrio é restaurado, o princípio da alavanca requer que a seguinte relação seja obedecida ${ }^{6}$ :

$F_{1} d_{1}=F_{2} d_{2}$

$F_{1}$ e $F_{2}$ são as forças que atuam sobre as arestas do prisma esquerdo e direito, respectivamente, e $d_{1}$ e $d_{2}$ são as respectivas distâncias destes prismas ao ponto de apoio central (o comprimento dos braços da balança - segmentos AO e OB, na Figura 2). Em geral, a balança tem braços iguais, donde $d_{1}=d_{2}$ e, portanto, $F_{1}=F_{2}$. A origem das forças $F_{1}$ e $F_{2}$ reside na atração da gravidade sobre os corpos que estão nos pratos da balança, e que podem ser expressas por:

$F_{1}=M_{1} g$ e $F_{2}=M_{2} g$

onde $M_{1}$ e $M_{2}$ são as massas que estão nos pratos da balança, e $g$ é a aceleração da gravidade.

A teoria da balança foi assunto de estudos do grego Aristóteles (384-322 a.C.), que decompôs o movimento dos braços da balança em seus componentes radial e tangencial. A obra Perì Cygôn (sobre alavancas) de Arquimedes (287-212 a.C.) contém as considerações principais sobre o centro de gravidade e o braço da alavanca. Contudo, a teoria completa da balança foi desenvolvida somente em 1747 , por Leonhard Euler (1707-1783), matemático e físico suíço ${ }^{6} . \mathrm{Na}$ década de 1870, Dimitri Mendeleev (1834-1907) reestudou a teoria física da balança ${ }^{7}$. O resultado de seus cálculos mostrou que uma exatidão de 1/15 mg com uma carga de $1 \mathrm{~kg}$ podia ser obtida com um tamanho de travessão até quatro vezes menor que os instrumentos da ocasião, resultado esse que teve influência na construção das balanças comercias a partir daquela época.

$\mathrm{O}$ uso da balança, independente do modelo, exige uma série de cuidados para que o resultado seja confiável e a durabilidade do instrumento seja elevada; isto inclui a eliminação de possíveis fontes de erros nas pesagens (empuxo, efeito de temperatura, eletricidade estática $)^{8}$.

\section{A BALANÇA DE DOIS PRATOS}

Admite-se que a balança tenha origem no Antigo Egito. Durante cerca de 40 séculos, a balança teve como característica a existência de dois pratos.

Desde a Antigüidade, a balança (Figura 4) sempre encontrou emprego nas áreas comercial e econômica de diversos povos (egípcios, babilônios, gregos, etruscos e romanos ${ }^{2,9,10}$ ). Afora esse emprego normal, a balança teve uma conotação mística em algumas civilizações. Por exemplo, as balanças dos antigos egípcios, representadas nos "Livros dos Mortos" (Figura 5) ${ }^{11}$, simbolicamente representavam a pesagem do coração do defunto contra o peso da verdade. Conforme as culpas carregadas pelo morto, a balança pendia para o prato do coração (destino, condenação da alma) ou da pena (destino, felicidade eterna). A balança, aqui, tinha uma simbologia associada à justiça ${ }^{2}$. Para os babilônios, a balança simbolizava a igualdade dos dias e das noites, já que o sol entrava na constelação de Libra no equinócio de Outono (quando o dia e a noite têm igual duração) ${ }^{10}$. Com efeito, de todos os signos do zodíaco, Libra é o único representado por um objeto: a balança ${ }^{11}$.

As balanças egípcias tinham dois braços iguais, sendo o travessão amarrado à haste, ou ainda fixado por orifícios unidos por um prego ou um anel (este ponto de apoio chama-se fulcro). Há ainda que se considerar os modelos onde a haste era suspensa pela mão, muito usadas nas farmácias e ourivesarias. Existiu também uma outra versão, de braços desiguais, usada em transações comerciais, sendo um dos pratos substituído por um peso fixo e o outro, por um gancho 


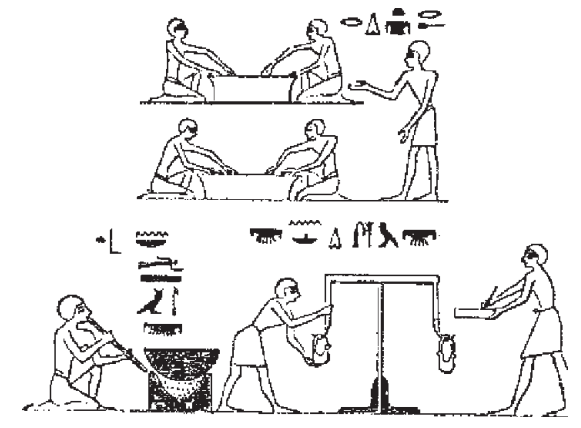

Figura 4. A metalurgia do ouro no Antigo Egito (ca. 1500 a. C), demonstrando o uso da balança. Reproduzida da ref. 10, com permissão de Journal of Chemical Education; copyright $\odot$ C 1934, Division of Chemical Education, Inc.

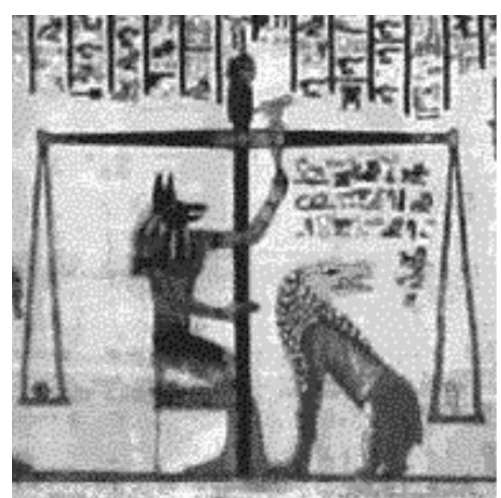

Figura 5. A pesagem do coração do defunto contra a verdade, em um dos “Livros dos Mortos" (fragmento do papiro de Hunefer, século XIII a. C.). Reproduzida da ref. 11, com permissão da Editora Espasa-Calpe; copyright (C) 1932.

onde se pendurava a carga. $\mathrm{O}$ braço maior tinha graduações e o peso fixo; o menor, o gancho para os objetos.

É na balança dos romanos que talvez se encontra o primeiro exemplo de sistema de travamento: em um desenho sugere-se que um dos braços fica imobilizado, evitando que o prato caia com a mercadoria antes da colocação dos pesos no outro prato ${ }^{2}$.

A análise de figuras e monumentos pictóricos do final da Idade Média indica que, aparentemente, não houve progresso sensível da técnica de construção da balança em mais de 30 séculos. Isso decorre fundamentalmente do emprego que era destinado à mesma, o qual era satisfeito com a tecnologia disponível. Além disso, deve-se considerar o pouco progresso dos processos químicos, após as contribuições de egípcios, babilônios e assírios ${ }^{2}$. $\mathrm{Na}$ época, as teorias e leis sobre a transformação da matéria e as pesquisas experimentais não justificavam melhorias no instrumento. É verdade que, mesmo durante a Baixa Idade Média, as proporções de massa das matériasprimas eram devidamente consideradas em certos experimentos, sendo também observadas mudanças de massa em alguns casos, mas estes eram ocasionais e tratados com empirismo. Do mesmo modo, cabe destacar que, nas farmácias, a balança sempre desempenhou papel essencial: os antigos médicos já escreviam receitas com indicações exatas de massa. Com o advento da iatroquímica (a precursora da química médica), por volta do século XVI, começou o uso de substâncias muito venenosas na composição dos remédios, daí uma pesagem mais rigorosa tornou-se necessária²

No século XVI, com o renascimento da tecnologia química, apareceram as primeiras grandes obras neste campo, onde a inserção da balança em atividades de pesquisa e o rigor em seu emprego começaram a tomar forma.

Por exemplo, Vannoccio Biringuccio (1480-1537) deu as primeiras indicações numéricas corretas sobre o aumento de massa na transformação do chumbo metálico em litargírio $(\mathrm{PbO})$ e mínio $\left(\mathrm{Pb}_{3} \mathrm{O}_{4}\right)$, com aumentos de massa de 8 até $10 \%$ (os valores exatos são, respectivamente, $7,7 \%$ e 10,3\%). Já era bem estabelecido que, de uma certa quantidade de matéria-prima, não se podia fabricar quantidades arbitrárias de um produto e que, quando se queria fabricar economicamente, se devia reagir quantidades exatamente determinadas ${ }^{2}$, o que valorizava o emprego da balança nos processos químicos.

Georgius Agricola (1494-1555), em sua obra principal, De Re Metallica (1556), atribuiu grande importância à balança ${ }^{12}$, mencionando três tipos, como aparece na Figura 6. A primeira balança (à direita) era destinada à pesagem bruta de fundentes, cimento ou chumbo; a segunda (à esquerda) mais sensível que a primeira, era usada para pesar o minério ou o metal a serem analisados. A terceira balança (ao fundo) dentro de uma vitrina, era a mais sensível e servia para a determinação da massa do produto resultante da cupelação. Notável é que todas as balanças possuíam dispositivos que permitiam levantá-las ou abaixá-las; quando não estavam em uso, os pratos eram abaixados até descansarem sobre a mesa, evitando desgaste inútil das partes móveis, o que aumentava a vida útil da mesma. Trata-se de um importante avanço da tecnologia de construção da balança. A colocação da balança numa vitrine isolava-a de correntes convectivas e do ambiente corrosivo de laboratório, prática sistematizada aos poucos, a partir daquela época.

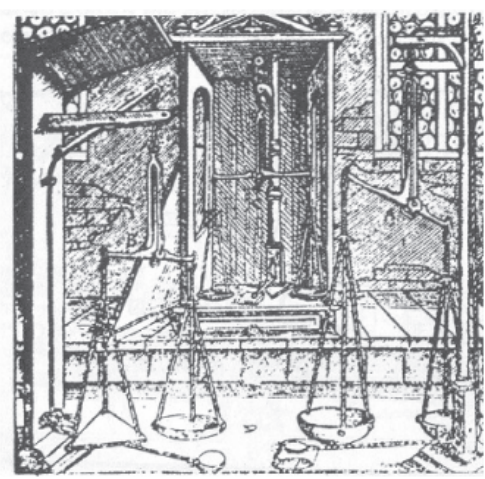

Figura 6. Balanças de Georgius Agricola (De Re Metallica, 1556). Reproduzida da ref. 12, com permissão de Journal of Chemical Education; copyright (C) 1929, Division of Chemical Education, Inc.

Além de Agricola, a pesagem em ambientes isolados era também mencionada por Lázaro Ecker (? -1593) e Andreas Libavius (1540-1616), que projetou em 1606 uma "casa ideal de química", onde havia uma sala para balanças ${ }^{13}$, das quais algumas em vitrine. Johann Joachim Becher (1635-1682), no seu catálogo ilustrado de um laboratório químico portátil (1680), descreveu os equipamentos mais necessários de um laboratório analítico, dentre os quais três balanças e entre elas, um modelo dentro de uma vitrine ${ }^{2,13}$.

Johann Baptist van Helmont (1577-1644) proclamou a absoluta necessidade do emprego da balança nas pesquisas científicas ${ }^{14}$. Joachim Jungius (1587-1657) também manifestou a opinião de que os processos químicos deviam ser investigados com auxílio da balança ${ }^{15}$. Em meados do século XVII, por conta da expansão da metalurgia, as balanças tornaram-se mais sensíveis a pequenas variações de massa (diminuição da massa do travessão) e os sistemas de pesos foram regulamentados ${ }^{2}$. A partir de 1760 apareceram muitos trabalhos de química quantitativa, fundamentada no emprego da balança.

No início do século XIX, a balança sofreu uma importante mu- 
dança estrutural. O travessão, antes diretamente ligado à haste da balança por meio do fulcro, passa a repousar sobre um apoio triangular (o cutelo). Na verdade, o cutelo já fora introduzido no final do século XVIII, mas sua popularização só se deu na virada para o século seguinte. Idealmente, os fulcros (pontos de apoio) da balança deveriam ser livres de qualquer atrito, o que não ocorria na prática, mas a adoção do cutelo reduziu bastante esse atrito, o que garantia maior sensibilidade da balança às variações de massa. Outro importante melhoramento foi a adoção da escala para observar melhor a deflexão do travessão (por meio do fiel da balança). Elas eram raramente usadas nos modelos de balança anteriores ao século XIX. Tudo o que se tinha era um ponteiro ligado ao travessão (ou ao fulcro), tanto voltado para cima como para baixo, este último se tornando dominante a partir do século XVIII.

Afora essas considerações iniciais, a balança passou por um novo período de estagnação quanto à evolução técnica. Porém, a sua utilização na Química teve extraordinário crescimento. A determinação da massa estava intimamente ligada à descoberta de leis ponderais e de novos elementos químicos, ao desenvolvimento da química orgânica e à evolução da análise quantitativa gravimétrica inorgânica e orgânica. Nesse aspecto, já se afirmava que "toda a operação química de precisão começa e termina na balança"16 (situação válida até hoje). Apesar de ter sido hoje em dia grandemente superada por métodos de análise quantitativa titrimétrica e instrumental, a gravimetria teve grande importância histórica na evolução da química experimental no século XIX, porque este era o único método sistemático de análise quantitativa existente naquele tempo. A separação do constituinte era efetuada essencialmente por precipitação química. O constituinte desejado era separado da amostra na forma de uma fase pura, de composição química definida, que então era pesada. A partir da massa desta última, achava-se a massa do constituinte através de relações estequiométricas apropriadas.

Martin Heinrich Klaproth (1743-1817), usuário intensivo da balança analítica, adotou técnicas e métodos analíticos que levaram a resultados mais rigorosos que os obtidos normalmente pelos outros químicos e suscitaram a descoberta de novos elementos. Na análise percentual de compostos minerais, por exemplo, mostrou que muitas vezes o valor que deixava de ser considerado para totalizar 100 poderia ser atribuído a novas substâncias. Assim, foi levado a descobrir algumas "terras": óxidos de zircônio, urânio, telúrio e titânio (estes compostos somente anos mais tarde forneceram os respectivos elementos usando métodos de redução ${ }^{17}$ ). Jöns Jacob Berzelius (17791848) modificou a técnica gravimétrica de Klaproth, considerada a melhor da época, usando quantidades consideravelmente menores das substâncias a analisar, introduzindo balanças mais sensíveis de uso analítico. A Figura 7 representa uma das balanças usadas por Berzelius em seus trabalhos ${ }^{2}$.

A melhoria da sensibilidade da balança teve capítulo especial no desenvolvimento da análise quantitativa orgânica. A partir do método da combustão controlada, desenvolvido por Justus von Liebig (1803-1873), que requeria uma quantidade de 0,5 a 1,0 g de material para análise, às vezes impraticável quando do isolamento de um produto natural, Fritz Pregl (1869-1930) introduziu um processo de microanálise em 1911, melhorando os instrumentos e acessórios envolvidos, especialmente a sensibilidade da balança. Com isso a massa necessária passou para a faixa 3-4 $\mathrm{mg}$, sendo ele premiado com o Nobel de Química em $1923^{18}$.

O alemão Karl Remigius Fresenius (1818-1897), em sua obra de Química Analítica Quantitativa ${ }^{19}$ (1885), dedicava um capítulo especial à balança. A partir de então, passou a ser cada vez mais freqüente, até tornar-se prática corriqueira, ensinar as técnicas de uso da balança em livros de Química Analítica, sendo geralmente o capítulo inicial desses livros. Na virada para o século XX, toda a teoria

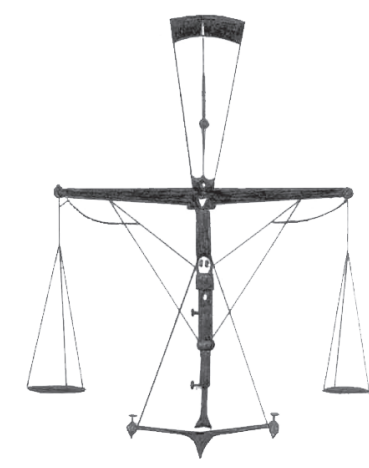

Figura 7. Representação de uma das balanças utilizadas por Berzelius (primeiras décadas do século XIX)

da balança analítica já estava plenamente desenvolvida (construção, técnicas de pesagem, etc) $)^{20,21}$.

Por volta de 1900, a balança assumiu papel especial na Química Analítica Qualitativa, dada a introdução da microanálise (que emprega quantidade de substâncias cerca de 100 vezes menores do que na macroanálise) e reagentes de maior sensibilidade e confiabilidade, o que exigia o preparo de soluções com menores concentrações dos analitos de interesse ${ }^{20}$.

O material de construção das balanças até o século XVIII variou bastante, podendo ser bronze, ouro, prata e mesmo a madeira ${ }^{2}$. Ao longo do século XIX, o latão foi largamente utilizado como matériaprima, vindo a seguir o cobre, especialmente para pesagens de moedas, metais preciosos e diamantes ${ }^{22}$. Os pesos já eram feitos de metal (latão especialmente) desde os tempos de Georgius Agricola ${ }^{12}$, mas na Antigüidade encontraram-se pesos feitos de outros materiais, como granito, sienito, basalto, gipso e hematita ${ }^{23}$. É evidente que os pesos tinham de ser feitos com materiais estáveis ao ar para que a exatidão dos mesmos não ficasse comprometida com o tempo.

Por volta de 1850 a balança já era comercializada por várias firmas $^{22}$, face à expansão da química experimental. A produção, antes artesanal, feita por exímios artesãos sob encomenda, não comportava mais a demanda pelo instrumento.

Em 1870, Florenz Sartorius (1846-1925), engenheiro alemão, a partir de uma peça de alumínio cedida por Friedrich Wöhler (18001882), desenvolveu uma balança extremamente leve, de braços curtos e encerrada em uma caixa de vidro, montada na própria estrutura da balança (Figura 8$)^{24}$. Isso contrariava duas tendências: (a) a fabricação das balanças separadamente das caixas de vidro (ou vitrines) e (b) a concepção da balança com braços longos. Idealmente, os braços e

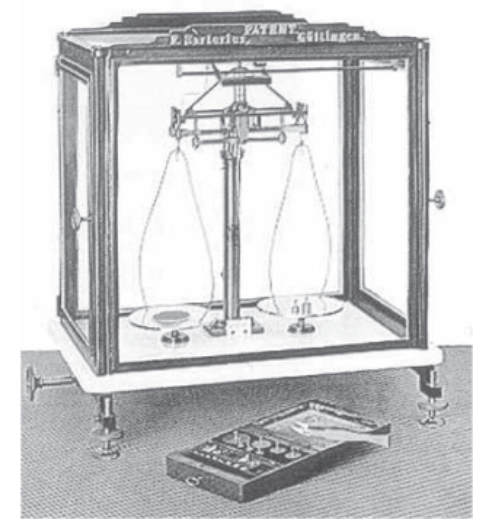

Figura 8. Modelo de balança analítica proposta por Sartorius em 1870, representando a forma clássica da balança de dois pratos, ao longo do século XX. Reproduzida da ref. 24, com permissão da Empresa Paralab 
seus acessórios deveriam ser infinitamente leves, o que não ocorria na prática $^{21}$; o uso do alumínio, metal mais leve que o cobre ou o bronze, melhorou enormemente a sensibilidade da balança. A facilidade de manejo e a precisão que se tinha com este modelo superavam largamente os resultados obtidos com as balanças da época. Tratava-se, assim, de uma revolução que marcou a história da balança por várias décadas. A teoria da balança, desenvolvida por Dimitri Mendeleev, ajudou na adoção do modelo proposto por Sartorius em escala comercial ${ }^{7}$.

As balanças começaram a figurar em catálogos nos anos 1870 , mas foi a partir de 1895 que se verificou uma grande diversificação de modelos, segundo a massa que deveriam determinar e o material de construção de que seriam feitas (latão, cobre, bronze, alumínio etc) ${ }^{25}$.

O final do século XIX testemunhou a incorporação definitiva da balança em todos os domínios da química, desde o ensino até a utilização industrial ${ }^{22}$. Nessa mesma época, a diversificação da química como ciência experimental levou à fabricação de dois tipos de balança de dois pratos (também conhecidas como balanças de dois pratos e três cutelos):

a) as chamadas balanças de mesa ou de bancada ("table balances"), destinadas à pesagem de líquidos corrosivos e sólidos que atacavam a balança analítica (iodo, por exemplo). Também eram empregadas nas medidas menos exatas de massa, onde a rapidez era primordial. A Figura 9 mostra dois modelos dessas balanças pertencentes ao acervo do Museu da Química Prof. Athos da Silveira Ramos $^{26}$, instalado no Instituto de Química da Universidade Federal do Rio de Janeiro. Ao contrário das balanças analíticas, elas não eram geralmente envolvidas por caixas protetoras e

b) as balanças analíticas, encerradas em caixas de vidro e madeira (eventualmente, metal), e muitas vezes colocadas em salas separadas, à parte do ambiente de laboratório.
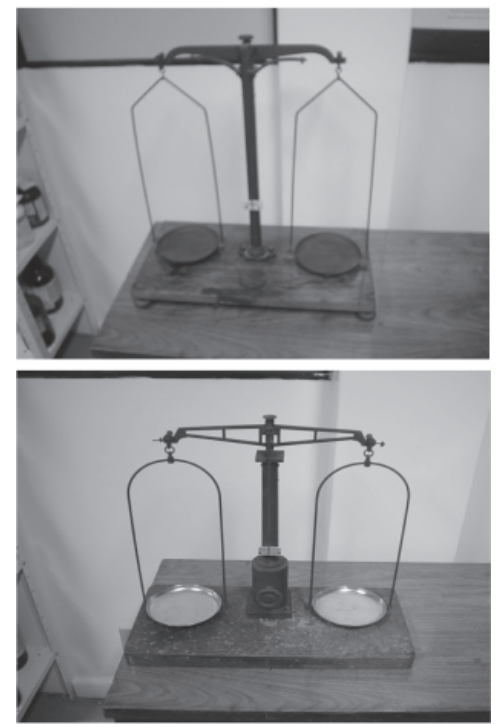

Figura 9. Balança de mesa de 2 pratos, em latão e base de madeira, origem alemã, ca. 1910 (acima); balança de mesa de 2 pratos, em aço e base de granito, origem americana, 1933 (abaixo). Acervo do Museu da Química Prof. Athos da Silveira Ramos

Popularizou-se no início do século XX o cavaleiro, que já fora proposto no século XIX por Johann Gottlieb Gahn (1745-1818)2,12. Sobre uma escala (geralmente de 0 a 100, com divisões), montada acima do travessão da balança, depositava-se em suas cavidades um pequeno peso em forma de gancho (mais tarde passou a ser de formato cilíndrico), o cavaleiro (Figura 10 ${ }^{20}$. Este era movido por meio de uma pinça controlada pelo lado de fora da balança. A adoção do cavaleiro dispensava o uso de pesos excessivamente pequenos (inferiores a $1 \mathrm{mg}$ ), de difícil fabricação. Conforme a construção do instrumento, o cavaleiro era capaz de detectar diferenças de massa inferiores a $1 \mathrm{mg}$ entre os pratos, dando ao mesmo uma sensibilidade de detecção da ordem de $0,1 \mathrm{mg}$.

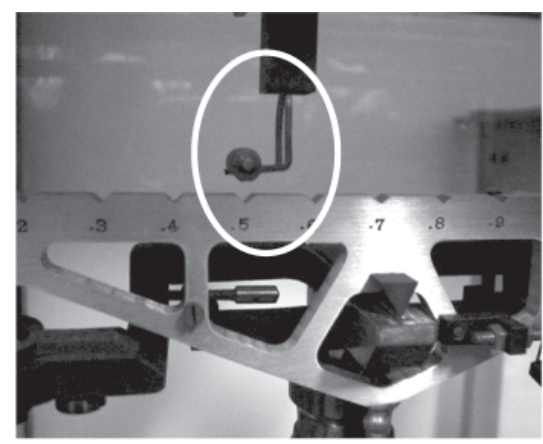

Figura 10. Em detalhe, esquema de parte da escala graduada do travessão de uma balança de dois pratos, onde se observa a manipulação do cavaleiro (formato cilíndrico) por meio de uma haste controlada do lado de fora do instrumento

Via de regra, as balanças eram fabricadas apoiadas sobre três pontos. O objetivo era restringir o movimento do instrumento à oscilação do travessão, do fiel, dos pratos e de seus suportes em um mesmo plano (perpendicular à base), evitando movimentos laterais vibratórios. Tratava-se de uma condição para a obtenção de medida confiável $^{20,21,27}$, além de reduzir o desgaste das partes móveis ${ }^{27}$. Um dos pontos de apoio correspondia a um parafuso ajustável, a fim de nivelar a base (ou plataforma) da balança em relação à bancada. É interessante assinalar que, a partir do início do século XX, os pontos de apoio passaram a ser, em geral, feitos de material polimérico (essencialmente baquelite), o qual transmite muito menos vibração da bancada à balança que os metais ${ }^{27}$.

Outra inovação foi a inclusão de sistemas de amortecimento dos pratos, que evitavam uma oscilação excessiva do instrumento, poupando as partes móveis de desgastes inúteis ${ }^{21}$.

A importância que a balança assumiu nos laboratórios foi tal, que livros específicos sobre o uso e a conservação deste instrumento foram editados ${ }^{28}$.

As técnicas de pesagem com a balança de dois pratos seguiam duas rotinas ${ }^{29}$ :

a) a pesagem por substituição pela técnica da sensibilidade (método de Borda), muito trabalhosa, mas que era a mais precisa de todas as técnicas. Neste caso, determinava-se a chamada curva de sensibilidade (sensibilidade na ordenada, contra a carga correspondente na abscissa), medindo-se o deslocamento do fiel com uma sobrecarga de $1 \mathrm{mg}$, para faixa de massa de 0 a $100 \mathrm{~g}$, a intervalos de $10 \mathrm{~g}$ (ou menos) e

b) a pesagem pela técnica do ajuste, que consistia em reconduzir a balança, em cada pesagem, ao mesmo ponto de equilíbrio por meio de deslocamentos sucessivos do cavaleiro. Avaliam-se assim os pesos até $\pm 0,1 \mathrm{mg}$ diretamente, pela simples posição do cavaleiro no travessão. A técnica tinha a desvantagem de obrigar a ajustes repetidos do cavaleiro até obter a posição correta, daí a sua denominação. Não apresentava a mesma exatidão do método de Borda, o que era compensado pela rapidez de execução. A técnica do ajuste era usada nas análises onde a rapidez era fundamental.

As pesagens eram de três modos: a pesagem direta consistia na determinação da massa de um objeto (vidro de relógio, cadinho) ou de um material delimitado. A pesagem por adição empregava-se na obtenção da massa exata, pré-fixada, de um sólido a granel ou de um 
líquido. A pesagem por diferença era destinada a substâncias que facilmente se alteravam em contato com o ar.

\section{A BALANÇA DE UM PRATO}

Durante décadas, as balanças de precisão enquadravam-se inteiramente apenas na modalidade de balanças de dois pratos, em concordância com o fato de o termo "balança", por si só, implicar no uso de dois pratos.

As balanças de um prato, também conhecidas como balanças de um prato e dois cutelos ou eletromecânicas, tornaram-se conhecidas somente a partir de 1946, quando Erhart Mettler (1917-2000) introduziu o primeiro modelo comercial prático no mercado científico ${ }^{30}$, que se expandia rapidamente após o fim da $2^{\mathrm{a}}$ Guerra Mundial. Estas balanças eram de custo muito mais alto que as de dois pratos, mas as conveniências por elas apresentadas tornaram-nas cada vez mais populares; as balanças de prato único começaram a substituir rapidamente os modelos de dois pratos a partir dos anos 1960.

Nesse instrumento (Figura 11), um dos pratos da balança e sua suspensão foram substituídos por um contrapeso ${ }^{8}$. Os pesos, suspensos sobre um eixo preso ao suporte do outro prato, são manipulados por um botão. Quando a balança está em repouso, todos os pesos estão colocados em posição no eixo. Ao se colocar um objeto sobre o prato da balança, os pesos são removidos do eixo para compensar a massa do objeto. A pesagem completa-se quando o travessão estiver novamente na posição de repouso. A leitura do deslocamento do travessão é feita em uma escala ótica calibrada para a leitura de valores inferiores a $100 \mathrm{mg}$. A pesagem, portanto, é feita por substituição (método de Borda) em balança de carga constante (por conseguinte, a sensibilidade não varia). Esta balança ainda está em uso em muitos laboratórios.

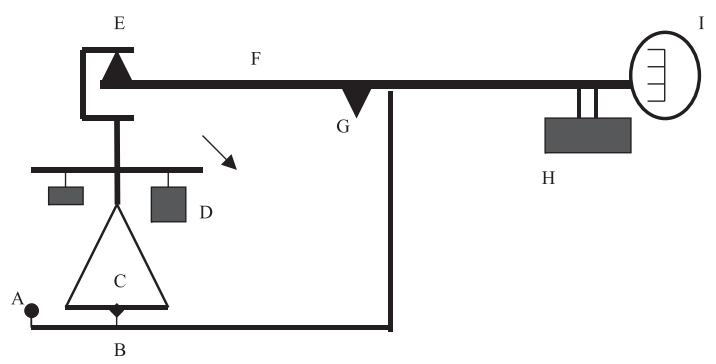

Figura 11. Esquema básico da balança de um prato: A: comando travadestrava; B: freio amortecedor do prato (atua quando a balança está travada); C: prato da balança; D: pesos; E: cutelo do jogo de pesos e do prato; F: travessão; G: cutelo central; H: contrapeso; I: escala ótica graduada

\section{A BALANÇA ELETRÔNICA}

No presente, o instrumento padrão é a balança eletrônica, onde a pesagem é mais conveniente, a possibilidade de falha mecânica é muito menor e a sensibilidade à vibração é muito reduzida. Esta balança elimina as operações de seleção e remoção de pesos, de liberação lenta do travessão e do suporte do prato, de anotação das leituras das escalas de pesos e da escala ótica, de retorno do travessão ao repouso e de recolocação dos pesos que foram removidos. A operação em uma única etapa permite a leitura, em um visor digital, da massa do objeto colocado no prato ${ }^{8}$. A maior parte das balanças possui o recurso da tara, que permite compensar a massa do recipiente, permitindo a leitura direta da massa do material adicionado. Elas incorporam um sistema interno de calibração de pesos, mas recomenda-se comparar as leituras contra uma série de pesos calibrados.
O princípio usado nas balanças eletrônicas (Figura 12) é a aplicação de uma força restauradora eletromagnética ao suporte do prato da balança ${ }^{8}$. O prato fica sobre um cilindro metálico oco, envolto por uma bobina que se ajusta no pólo interno de um ímã cilíndrico. Uma corrente elétrica na bobina cria um campo magnético que suporta ou levita o cilindro, o prato, um braço indicador e o objeto sobre o prato. A corrente é ajustada, de modo que o nível do braço indicador fique na posição nula quando o prato está vazio. Quando um objeto é colocado no prato da balança, o deslocamento do suporte é compensado. O braço indicador e o próprio prato movem-se para baixo, o que aumenta a quantidade de luz que atinge a fotocélula do indicador de nulidade. A intensidade da força restauradora é controlada pela corrente que passa pelas bobinas do sistema de compensação eletromagnética, que, por usa vez, é proporcional à massa adicionada. A corrente da fotocélula é então amplificada e passa a alimentar a bobina, criando assim um campo magnético maior, o que faz o prato voltar à sua posição original. A corrente necessária para manter o prato e o objeto na posição nula é diretamente proporcional à massa do objeto. Um microprocessador converte a intensidade de corrente em massa, sendo mostrada no visor. As balanças eletrônicas são de vários tipos, com leituras de escala indo desde $0,1 \mathrm{mg}$ (macrobalança) até $0,1 \mu \mathrm{g}$ (ultramicrobalança).

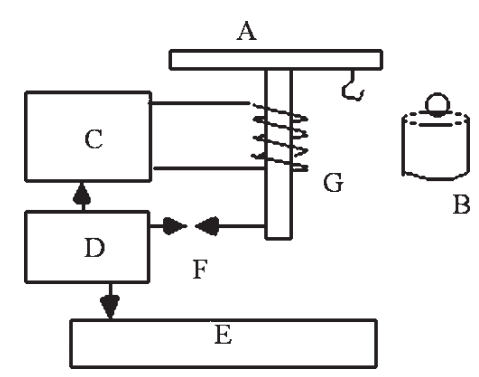

Figura 12. Princípio básico da balança eletrônica: A: prato da balança; $B$ : peso interno para calibração; $C$ : corrente; D: processador (o qual controla a calibração, a tara e o liga-desliga do aparelho); E: visor digital da massa; F: sensor; G: bobina

A Figura 13 mostra um exemplo de balança deste tipo, sendo também comparada aos outros modelos de balanças empregados no século XX.

\section{A MICROBALANÇA}

Embora hoje a microbalança seja uma espécie de subclasse das balanças digitais, sua menção justifica-se pela necessidade do desenvolvimento de um instrumento capaz de medir as menores variações de massa, que uma balança analítica comum não é capaz de detectar. Nos anos 1950, os primeiros protótipos foram testados ${ }^{24,30}$, mas precisou-se esperar a década seguinte para que os primeiros modelos comerciais fossem lançados, devido à popularização do transistor e do diodo, o que permitiu reduzir o tamanho do aparelho.

O princípio de funcionamento de uma microbalança é similar ao da balança eletrônica. O primeiro modelo fabricado no Brasil, no Centro Brasileiro de Pesquisas Físicas (CBPF - Figura 14), é capaz de detectar massas da ordem de $1 \mu \mathrm{g}\left(10^{-6} \mathrm{~g}\right)$.

\section{CONCLUSÕES}

O desenvolvimento da balança mostrou-se fortemente dependente das necessidades de seu emprego. Somente quando da sua valorização em processos químicos e investigativos, foram introduzidas melhorias na concepção do instrumento. Em particular, a sensibili- 

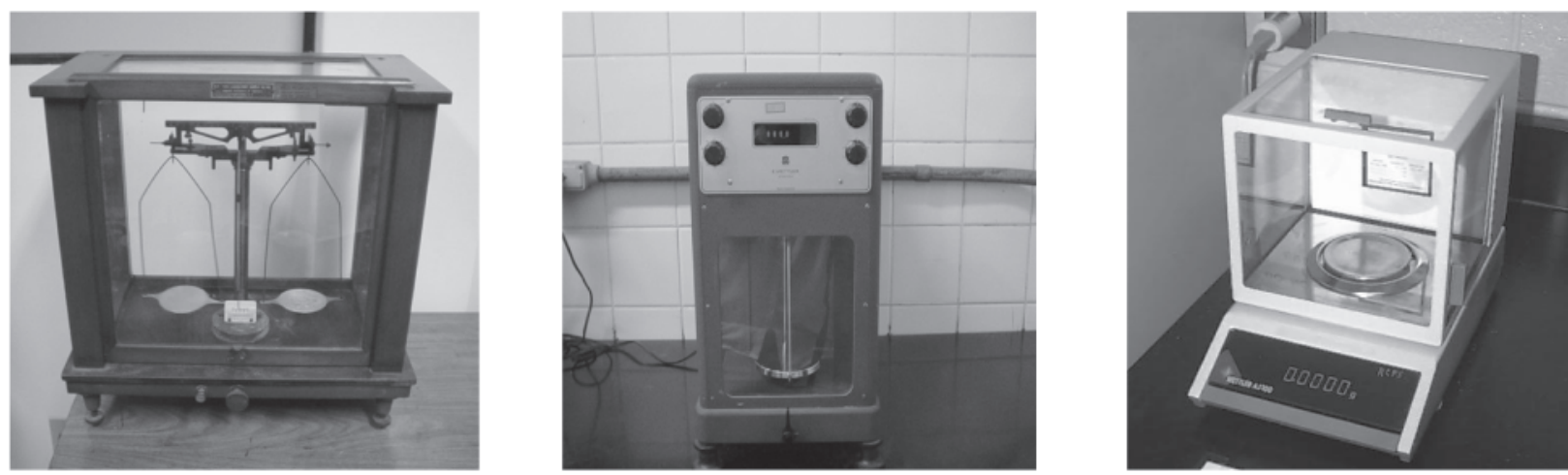

Figura 13. A evolução das balanças analíticas no século XX. À esquerda: balança analítica clássica de dois pratos, origem americana, 1932. Ao centro: balança de um prato, origem suíça, 1960. À direita: balança eletrônica moderna, origem suíça, 2000. Acervo do Museu da Química Prof. Athos da Silveira Ramos

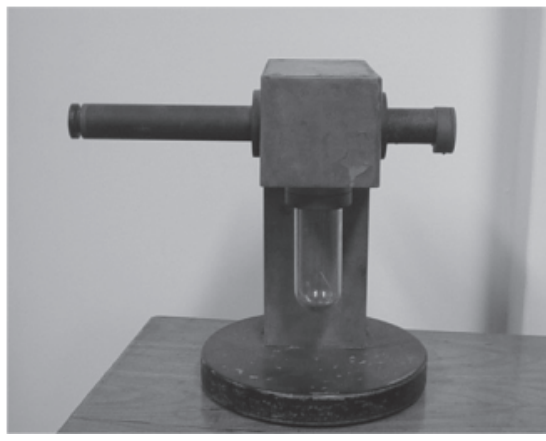

Figura 14. A $1^{a}$ microbalança fabricada no Brasil, no Centro Brasileiro de Pesquisas Físicas (CBPF), construída pelo Prof. François Karl Neitz, em 1968. Acervo do Museu da Química Prof. Athos da Silveira Ramos

dade foi parâmetro crucial no desenvolvimento de balanças capazes de detectar menores variações de massa.

A partir do século XIX a balança assumiu um papel primordial nas investigações realizadas pelos químicos, tornando-a instrumento vital em qualquer laboratório, preceito válido até hoje.

Uma vez estabelecida sua importância, a balança passou a sofrer aperfeiçoamentos significativos a partir do final do século XIX, movidos pelo desejo de produzir um instrumento mais robusto, menos dependente da prática do operador, menos sensível ao ambiente e que, acima de tudo, tornasse a operação de pesagem mais rápida. Para tal, o desenho das balanças analíticas foi fundamentalmente modificado, sendo a característica marcante do século XX: a tradicional balança de dois pratos, acompanhada de sua caixa de pesos, cedeu vez aos modelos de um só prato, que foram substituídos pelas balanças eletrônicas.

\section{AGRADECIMENTOS}

À Fundação José Bonifácio (FUJB) pelo auxílio financeiro. A C. A. L. Filgueiras (IQ/UFRJ) e N. P. dos Santos (IQ/UFRJ) pela análise crítica deste trabalho.

\section{REFERÊNCIAS}

1. Lopes, A. R. C.; Química Nova na Escola 1995, nº 2, 11.

2. Rheinboldt, H.; A História da Balança, A Vida de J. J. Berzelius, Nova Stella Editorial e Ed. da Universidade de São Paulo: São Paulo, 1988.

3. Benedicenti, A.; Malati Medici e Farmacisti, Hoeple: Milão, 1925, p. 910.

4. Martins, R. A.; Quim. Nova 1993, 16, 481; Martins, R. A.; Martins, L. A. P.; Quim. Nova 1993, 16, 245; Filgueiras, C. A. L.; Lavoisier - O Estabelecimento da Química Moderna, Odysseus: São Paulo, 2002.
5. Holmyard, E. J.; Chemistry to the Time of Dalton, Oxford University Press: Londres, 1925, p. 111-125.

6. Hoppe, H.; Histoire de La Physique, Payot: Paris, 1928, p. 19-25; Barral, E.; Précis d'Analyse Chimique Quantitative, J. B. Baillière et Fils: Paris, 1905, vol. 1, p. 13-29.

7. http://www.spbu.ru/Structure/Culture/Museums/Mendeleev/enhist.html, acessada em Março 2003.

8. Vogel, A. I.; Análise Química Quantitativa, 6a ed., Livros Técnicos e Científicos: Rio de Janeiro, 2002, p. 36-39.

9. Enciclopédia Italiana, Roma, 1968, vol. XIII, p. 324

10. Warren, L. E.; J. Chem. Educ. 1934, 11, 149.

11. Goetz, W.; Historia Universal, Espasa-Calpe: Madrid, 1932, vol. I, p. 376-377.

12. Billinger, R. D.; J. Chem. Educ. 1929, 6, 353.

13. Landenburg, A.; Allgemeine Deutsche Biographie, 1883, vol. XVIII, p. 531.

14. Hoefer, F.; Nouvelle Biographie Générale, Firmin Didiot: Paris, 1858, vol. XXIII, p. 856; vol. XLIV, p. 397-402.

15. Lepsius, B.; Allgemeine Deutsche Biographie, 1893, vol. XXXV, p. 780786.

16. Chittenden, R. H.; The Development of Phisyological Chemistry in the United States, The American Chemical Monograph: Nova Iorque, 1930, p. 227.

17. Senise, P.; Quim. Nova 1993, 16, 257.

18. Allinger, N. L.; Cava, M. P.; de Jongh, D. C.; Johnson, C. R.; Lebel, N. A.; Stevens, C. L.; Química Orgânica, Guanabara Dois: São Paulo, 1978, p. 8-11.

19. Fresenius, K. R.; Chimie Analytique Quantitative, Gauthier-Villards et Fils: Paris, 1885, cap. 1

20. Blasdale, W. C.; Principles of Quantitative Analysis, D. van Nostrand Company: Nova Iorque, 1918, cap. 1.

21. Mellon, M. G.; Methods of Quantitative Chemical Analysis, The Macmillan Company: Nova Iorque, 1937, p. 44-45.

22. Joannis, A.; Encyclopédie Industrielle - Traité de Chimie Organique Appliquée, Gauthier-Villards et Fils: Paris, 1896, vol. 1, p. 45-94.

23. Petrie, W. M. K.; Encyclopaedia Britannica, 1937, 14 a ed., vol. XV, p. 142-145.

24. http://www.paralab.pt/sartorius.htm, acessada em Novembro 2002.

25. http://www.humboldt.edu/ scimus/Manufac/C_Becker/ BeckerCat50_70.htm, acessada em Março 2003.

26. Athos da Silveira Ramos (1906-2002), um dos fundadores do Instituto de Química da UFRJ, sendo seu primeiro presidente. De carreira brilhante, testemunhou in loco o nascimento do Museu que leva seu nome e as duas primeiras exposições realizadas. Os detalhes completos sobre sua trajetória profissional podem ser encontrados em Espínola, A.; Coimbra, A. L. G.; Perlingeiro, C. A. G.; Martelli, H. H. L.; Mano, E. B.; Quim. Nova 2002, 25,340 .

27. Waldron, K. J.; Kinematics, Dynamics and Design of Machinery, John Wiley \& Sons: Nova Iorque, 1999.

28. Krayer, P. J.; The Use and Care of a Balance; The Chemical Publishing Company: Washington, 1913.

29. Krauledat, W. G.; Práticas de Análise Volumétrica, Instituto de Química, Universidade Federal do Rio de Janeiro: Rio de Janeiro, 1969, vol. B1, p. 6-16.

30. http://www.mettler.com, acessada em Dezembro 2002. 